\title{
BEHAVIOR OF CALCIUM SULFATE AT HIGH TEMPERATURES
}

\author{
By Edwin S. Newman
}

\section{ABSTRACT}

Differential heating curves were used to study the behavior of calcium sulfate at high temperatures. After cooling, the material was examined by means of the petrographic microscope and by study of its X-ray pattern. It was found that the beta-to-alpha transition of calcium sulfate occurs at approximately $1,214^{\circ} \mathrm{C}$, and the conclusion of its discoverer that the high temperature form is unstable was confirmed. There appears to exist a eutectic mixture of alpha $\mathrm{CaSO}_{4}$ and $\mathrm{CaO}$ which melts at approximately $1,365^{\circ} \mathrm{C}$. The reported existence of basic sulfates of calcium was not confirmed.

\section{CONTENTS}

I. Introduction

II. Materials _...

III. Procedure

IV. Results and discussion _.

V. Summary _........ 195

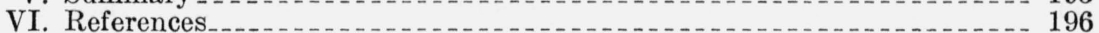

\section{INTRODUCTION}

The behavior of pure calcium sulfate is of interest in considering the properties of those types of calcium sulfate cements or plasters which are prepared by heating the raw material to a very high temperature. Several plants are in existence abroad at which calcium sulfate is used as one of the raw materials for the manufacture of portland cement and sulfuric acid, advantage being taken of the decomposition of calcium sulfate to lime and sulfur trioxide at high temperatures. This decomposition is presumably responsible in part for the absence of $\mathrm{CaSO}_{4}$ in many portland cement clinkers made in the ordinary way, as has been reported recently by the National Bureau of Standards [1]..$^{1}$

Naturally occurring calcium sulfate is found in two forms, as gypsum with 2 molecules of water of crystallization and as anhydrite containing no water of crystallization. By heating gypsum at successively higher temperatures four modifications can be prepared in order as follows: (1) the hemihydrate, $\mathrm{CaSO}_{4} \cdot \frac{1}{2} \mathrm{H}_{2} \mathrm{O}$, of which plaster of paris is largely composed; (2) an extremely hygroscopic anhydrous form known as soluble anhydrite which changes rapidly to the hemihydrate in the presence of water vapor; (3) an anhydrous modification identical with the naturally occurring anhydrous calcium sulfate mentioned above; (4) and at approximately $1,200^{\circ} \mathrm{C}$ a high-temperature form

\footnotetext{
1 Figures in brackets indicate the literature references at the end of this paper.
} 
stable, except for decomposition, only at this and higher temperatures [2]. At such temperatures the decomposition of $\mathrm{CaSO}_{4}$ to $\mathrm{CaO}$ and $\mathrm{SO}_{3}$ becomes appreciable. The total equilibrium pressure of $\mathrm{SO}_{3}$, $\mathrm{SO}_{2}$, and $\mathrm{O}_{2}$ over calcium sulfate has been measured $[3,4]$ and found to be approximately $100 \mathrm{~mm}$ at $1,225^{\circ} \mathrm{C}$. The decomposition pressure increases rapidly with increase of temperature, and extrapolation of Marchal's data [3] indicates that it probably reaches 1 atmosphere in the neighborhood of $1,400^{\circ} \mathrm{C}$. The presence of 30 percent of alumina, 43 percent of silica, or 35 percent of kaolin lowers the decomposition temperature [3] to about $1,350^{\circ}, 1,275^{\circ}$, and $1,150^{\circ} \mathrm{C}$, respectively. This is presumably responsible in part for the absence of calcium sulfate [1] in many portland cement clinkers, since the total equilibrium pressure of $\mathrm{SO}_{3}, \mathrm{SO}_{2}$, and $\mathrm{O}_{2}$ over a mixture containing calcium sulfate, silica, and alumina may be expected to be several atmospheres at clinkering temperatures.

The transition of the ordinary forms of anhydrite to the hightemperature modification was reported to occur at $1,196^{\circ} \mathrm{C}$ by Grahmann [2], who studied the material by means of a petrographic microscope equipped with a furnace for maintaining the sample at high temperatures. Abrupt changes in interference colors observed when a single crystal was heated and the appearance of the crystal on cooling served, together with heating and cooling curves, to identify a transition and fix its temperature. Masuda [5] reported that this transition occurred at $1,232^{\circ} \mathrm{C}$, and unpublished data obtained by the writer indicated that the transition took place at an intermediate temperature. Because of the large variation in the reported temperature of transition, it was decided to report these data together with further studies of the behavior of calcium sulfate at elevated temperatures and of the system $\mathrm{CaO}-\mathrm{CaSO}_{4}$.

\section{MATERIALS}

Artificial anhydrite, $\mathrm{CaSO}_{4}$, was prepared by heating $\mathrm{CaSO}_{4} \cdot 2 \mathrm{H}_{2} \mathrm{O}$ of analytical reagent quality for 1 hour at $600^{\circ} \mathrm{C}$. Natural anhydrite from Midland, Calif., was ground to pass a No. 200 sieve. Analyses indicated that the mineral contained 0.15 percent of $\mathrm{SiO}_{2}, 0.15$ percent of $\mathrm{Al}_{2} \mathrm{O}_{3}+\mathrm{Fe}_{2} \mathrm{O}_{3}$, and 0.06 percent of $\mathrm{MgO}$. The loss on ignition was 1.6 percent, including 0.9 percent of $\mathrm{CO}_{2}$. Calcium carbonate of reagent quality was used for a source of lime in preparing mixtures of $\mathrm{CaSO}_{4}$ and $\mathrm{CaO}$. These mixtures were prepared by stirring the artificial anhydrite and calcium carbonate together in the desired proportions with sufficient distilled water to form a slurry, which after thorough mixing was evaporated to dryness and ground in an agate mortar to pass a No. 100 sieve. Subsequently the mixtures were ignited at $950^{\circ} \mathrm{C}$ for 2 hours to remove carbon dioxide.

\section{PROCEDURE}

Heating and cooling curves were obtained by means of a differential thermocouple of $\mathrm{Pt}: \mathrm{Pt}-10$-percent $\mathrm{Rh}$ in a small vertical tube furnace. The $\mathrm{CaSO}_{4}$ and $\mathrm{Al}_{2} \mathrm{O}_{3}$ as the reference material were placed, respectively, in two small semicircular crucibles, $1 / 2$ inch in outside diameter and 1 inch deep, with a capacity of about $2 \mathrm{~g}$ of powdered material. The two hot junctions of the differential thermocouple were embedded 


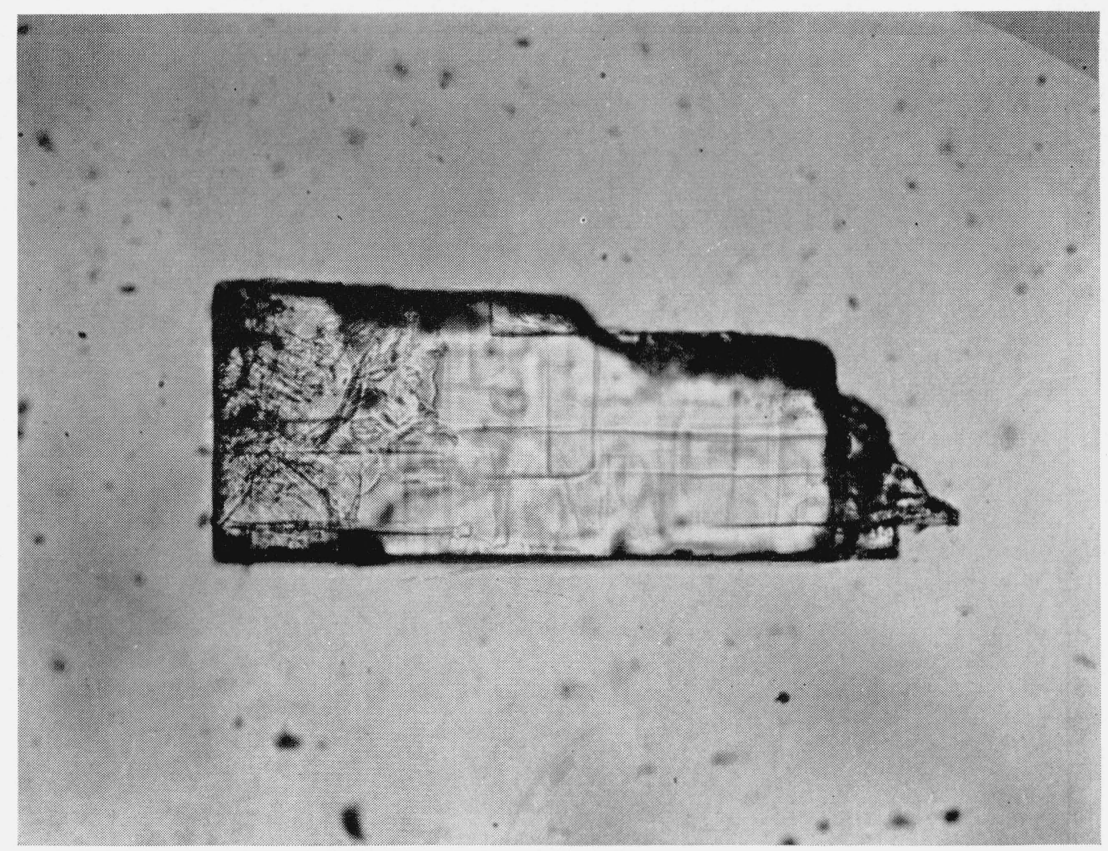

FiguRe 1.-Crystal of anhydrite after heating 10 minutes at $1,213^{\circ} \mathrm{C} ; \times 50$.

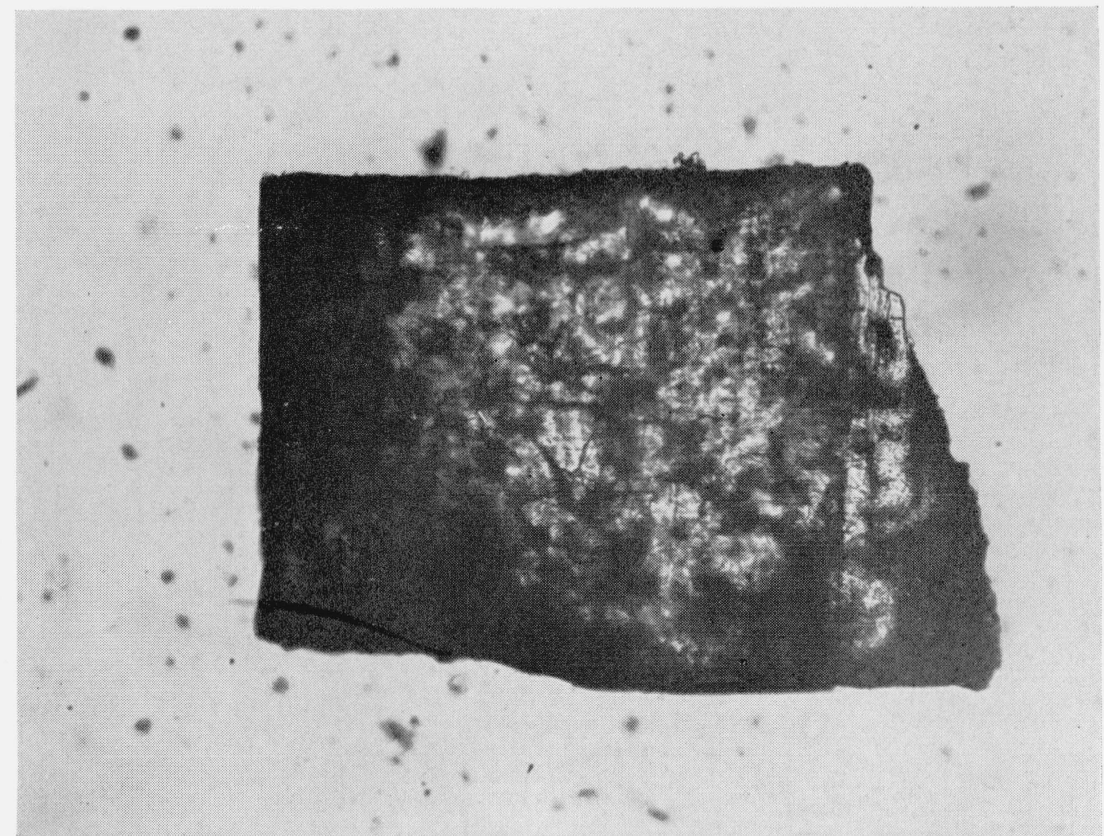

FiguRE 2.-Crystal of anhydrite after heating 10 minutes at $1,217^{\circ} \mathrm{C} ; \times 50$. 
in the two materials and the crucibles suspended in the furnace. The emf developed by the hot junction in the $\mathrm{CaSO}_{4}$ was measured by means of a precision potentiometer, and differences in temperature between the two hot junctions were indicated by the deflections of a galvanometer. The rates of heating or cooling, which were maintained constant during the series of readings taken for any one heating curve, ranged from $2^{\circ}$ to $5^{\circ} \mathrm{C}$ per minute. The potentiometer reading and the deflection of the galvanometer were recorded every minute, or oftener if they were changing rapidly. A few small charges wrapped in platinum foil were heated and then quenched in water or mercury. These samples were then examined by means of the petrographic microscope and by study of their X-ray patterns. The thermocouples were calibrated by the Bureau, and the differential thermocouple was checked occasionally against the melting point of $\mathrm{CaO} \cdot \mathrm{B}_{2} \mathrm{O}_{3}\left(1,154^{\circ} \mathrm{C}\right)$ [6] and the beta-to-alpha transition of $2 \mathrm{CaO} \cdot \mathrm{SiO}_{2}\left(1,420^{\circ} \mathrm{C}\right)$ [7].

\section{RESULTS AND DISCUSSION}

The results are given in table 1. Examination of these data shows that the reversible transition of the ordinary form of anhydrite to the high-temperature modification occurs at approximately $1,214^{\circ} \mathrm{C}$. The presence of large amounts of $\mathrm{CaO}$ (up to 76 percent) did not appear to alter this temperature significantly. The temperature at which the transition occurs was further substantiated by the following procedure. Fragments of natural anhydrite were heated for 10 minutes at $1,210^{\circ}$ to $1,220^{\circ} \mathrm{C}$, cooled, and examined. Although heating below $1,214^{\circ} \mathrm{C}$ caused no visual change, higher temperatures caused the particles to become opaque and under the microscope they were seen to be made up of crystallites at random orientation. This change is illustrated by photomicrographs taken by ordinary transmitted light of two such fragments after heating, one at $1,213^{\circ} \mathrm{C}$ (fig. 1) and the other at $1,217^{\circ} \mathrm{C}$ (fig. 2). The crystallites appeared to be the ordinary or beta form. Attempts to obtain alpha calcium sulfate at room temperature by quenching samples heated above the transition temperature were unsuccessful.

Another reversible thermal effect occurs on heating anhydrite to still higher temperatures. Frequently this is not found the first time the material is heated but is manifested upon cooling, and thereafter the deflections of the galvanometer become more pronounced as the heating and cooling cycles are continued. The average temperature at which this thermal effect appeared on heating artificial anhydrite was $1,371^{\circ}$ C. Natural anhydrite gave a somewhat lower value, owing perhaps to the presence of the other materials indicated by the analysis. Considerable supercooling occurs; the average temperature at which the breaks occurred in the cooling curves was $1,340^{\circ}$ and $1,329^{\circ} \mathrm{C}$ for the artificial and natural anhydrites, respectively. This thermal effect corresponds to the inflection which Grahmann [2] occasionally found in the cooling curve at $1,320^{\circ}$ to $1,370^{\circ} \mathrm{C}$.

In the present work the appearance of the contents of the crucible after heating was not uniform, but in many cases the anhydrite appeared to have fused when the temperature had at no time exceeded $1,390^{\circ} \mathrm{C}$. Since the temperature at which the thermal effect occurred was not greatly altered by the presence of large amounts of lime, the conclusion was drawn that it is caused by the melting and freezing of 
TABLE 1.-Temperature of alpha-beta transition and of eutectic melting observed with calcium sulfate and with calcium sulfate-lime mixtures

\begin{tabular}{|c|c|c|c|c|c|c|c|c|c|c|c|c|c|}
\hline \multicolumn{4}{|c|}{ Natural anhydrite a } & \multicolumn{4}{|c|}{ Artificial anhydrite b } & \multicolumn{6}{|c|}{ Calcium sulfate-lime mixtures $\circ$} \\
\hline \multicolumn{2}{|c|}{ Transition temperature } & \multicolumn{2}{|c|}{ Eutectic temperature } & \multicolumn{2}{|c|}{ Transition temperature } & \multicolumn{2}{|c|}{ Eutectic temperature } & \multirow{2}{*}{$\mathrm{CaOd}$} & \multicolumn{2}{|c|}{ Transition temperature } & \multicolumn{2}{|c|}{ Eutectic temperature } & \multirow[b]{2}{*}{$\begin{array}{l}\mathrm{CaO} \text { after } \\
\text { heating }\end{array}$} \\
\hline $\begin{array}{c}\text { From } \\
\text { heating } \\
\text { curves }\end{array}$ & $\begin{array}{l}\text { From } \\
\text { cooling } \\
\text { curves }\end{array}$ & $\begin{array}{c}\text { From } \\
\text { heating } \\
\text { curves }\end{array}$ & $\begin{array}{l}\text { From } \\
\text { cooling } \\
\text { curves }\end{array}$ & $\begin{array}{l}\text { From } \\
\text { heating } \\
\text { curves }\end{array}$ & $\begin{array}{l}\text { From } \\
\text { cooling } \\
\text { curves }\end{array}$ & $\begin{array}{c}\text { From } \\
\text { heating } \\
\text { curves }\end{array}$ & $\begin{array}{l}\text { From } \\
\text { cooling } \\
\text { curves }\end{array}$ & & $\begin{array}{c}\text { From } \\
\text { heating } \\
\text { curves }\end{array}$ & $\begin{array}{l}\text { From } \\
\text { cooling } \\
\text { curves }\end{array}$ & $\begin{array}{c}\text { From } \\
\text { heating } \\
\text { curves }\end{array}$ & $\begin{array}{l}\text { From } \\
\text { cooling } \\
\text { curves }\end{array}$ & \\
\hline $\begin{array}{r}{ }^{\circ} C \\
1,213 \\
1,215 \\
1,214 \\
1,212 \\
1,211\end{array}$ & $\begin{array}{l}{ }^{\circ} C \\
1,193 \\
1,214 \\
1,201 \\
1,199 \\
1,207\end{array}$ & $\begin{array}{l}{ }^{\circ} C \\
1,345 \\
1,360 \\
1,359 \\
1,350 \\
1,348\end{array}$ & $\begin{array}{l}{ }^{\circ} C \\
1,314 \\
1,333 \\
1,328 \\
1,327 \\
1,323\end{array}$ & $\begin{array}{l}{ }^{\circ} C \\
1,216 \\
1,220 \\
1,214 \\
1,213 \\
1,215\end{array}$ & $\begin{array}{l}{ }^{\circ} C \\
1,198 \\
1,196 \\
1,196 \\
1,193 \\
1,214\end{array}$ & $\begin{array}{l}{ }^{\circ} C \\
1,367 \\
1,371 \\
1,375 \\
1,356 \\
1,371\end{array}$ & $\begin{array}{l}{ }^{\circ} C \\
1,338 \\
1,346 \\
1,348 \\
1,348 \\
1,327\end{array}$ & $\begin{array}{cc}\% & \\
& 12 \\
& 17 \\
& 29 \\
& 45 \\
& 76\end{array}$ & $\begin{array}{l}{ }^{\circ} C \\
1,217 \\
1,213 \\
1,213 \\
1,214 \\
1,219\end{array}$ & $\begin{array}{l}{ }^{\circ} C \\
(e) \\
(\mathrm{e}) \\
1,202 \\
(\mathrm{e}) \\
1,202\end{array}$ & $\begin{array}{l}{ }^{\circ} C \\
1,371 \\
1,362 \\
1,369 \\
1,364 \\
1,351\end{array}$ & $\begin{array}{l}{ }^{\circ} C \\
1,350 \\
(\mathrm{e}) \\
1,349 \\
(\mathrm{e}) \\
1,337\end{array}$ & $\begin{array}{ll}\% & \\
\text { (e) } & 20 \\
& 35 \\
& 55 \\
& 83\end{array}$ \\
\hline $\begin{array}{l}1,215 \\
1,215 \\
1,217 \\
1,214 \\
1,209\end{array}$ & $\begin{array}{l}1,205 \\
1,203 \\
1,202 \\
1,198 \\
1,202\end{array}$ & $\begin{array}{l}1,367 \\
1,384 \\
\end{array}$ & 1,350 & $\begin{array}{l}1,214 \\
1,216 \\
1,216 \\
1,212 \\
1,214\end{array}$ & $\begin{array}{l}1,200 \\
1,196 \\
1,199\end{array}$ & $\begin{array}{l}1,376 \\
1,377 \\
1,377 \\
1,367\end{array}$ & $\begin{array}{l}1,332 \\
1,342 \\
1,341 \\
1,338 \\
1,336\end{array}$ & 93 & (i) & (f) & $(\mathrm{f})$ & $(f)$ & \begin{tabular}{r}
100 \\
\hdashline \\
\end{tabular} \\
\hline 1,216 & . & - & & 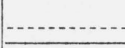 & & .. & 1,345 & & & & 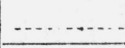 & & \\
\hline Average _.1, 214 & 1,202 & 1,359 & 1,329 & 1,215 & 1,199 & 1,371 & 1,340 & $\cdots$ & 1,215 & 1,202 & 1,363 & 1,345 & \\
\hline
\end{tabular}

a From Midland, Calif.

$\mathrm{R}_{2} \mathrm{O}_{3}+\mathrm{MgO}+\mathrm{SiO}_{2}=0.5$ percent;

loss on ignition $=1.6$ percent.

b Prepared by heating $\mathrm{CaSO}_{4} .2 \mathrm{H}_{2} \mathrm{O}$ of analytical reagent quality for 1 hour at $600^{\circ} \mathrm{C}$

- Prepared by heating mixtures of artificial anhydrite (footnote b) and calcium carbonate

d Original composition, calculated.

Not observed, insufficient $\mathrm{CaSO}_{4}$ in mixture to give observable deflection of of reagent quality. 
a eutectic mixture of the high-temperature form of $\mathrm{CaSO}_{4}$ and $\mathrm{CaO}$. The latter is produced by the decomposition of part of the $\mathrm{CaSO}_{4}$, the $\mathrm{SO}_{3}$ escaping as a gaseous product. This eutectic is probably low in $\mathrm{CaO}$ content, since mixtures originally containing more than 20 percent of $\mathrm{CaO}$ did not form sufficient liquid to allow the charge to present the physical appearance of having melted, although as will be seen in table 1 the thermal effect corresponding to the melting of the eutectic was observed. On the other hand, samples originally consisting of pure $\mathrm{CaSO}_{4}$ appeared to have melted when analyses showed that only from 4 to 12 percent of $\mathrm{CaO}$ had been formed. Attempts to obtain segments of the liquidus curve failed since no further heat effects were observed in any experiment between the melting of the eutectic and the limit of the furnace, $1,545^{\circ} \mathrm{C}$. This was presumably due to the decomposition of the $\mathrm{CaSO}_{4}$, which, on the assumption that the eutectic is low in lime, would have shifted the composition in the direction of high-melting mixtures. It is apparent that a closed apparatus must be used in a precise study of this system. However, it is interesting to note that Grahmann [2], using a 20-g sample of $\mathrm{CaSO}_{4}$, observed melting at $1,450^{\circ} \mathrm{C}$ and reported this value as the melting point of pure $\mathrm{CaSO}_{4}$. On the basis of this investigation Grahmann's result may be interpreted as representing a point on the liquidus curve, the true melting point being higher.

Although compounds of $\mathrm{CaO}$ and $\mathrm{SO}_{3}$ corresponding to the formulas $2 \mathrm{CaO} \cdot \mathrm{SO}_{3}$ [4] and $3 \mathrm{CaO} \cdot 2 \mathrm{CaSO}_{4}$ [8] have been reported, their existence was not confirmed in the present work. X-ray patterns were prepared of samples of both natural and artificial anhydrites quenched from temperatures ranging from $1,200^{\circ}$ to $1,545^{\circ} \mathrm{C}$, and of mixtures of anhydrite and $\mathrm{CaO}$ quenched from temperatures between $1,300^{\circ}$ and $1,545^{\circ} \mathrm{C}$. In only two cases were lines found in the X-ray patterns that did not correspond with lines in the patterns of anhydrite, $\mathrm{CaO}$ or $\mathrm{Ca}(\mathrm{OH})_{2}$ (in samples quenched in water or partly hydrated by atmospheric moisture). Two samples of a mixture originally of the proportions $2 \mathrm{CaO}: 1 \mathrm{SO}_{3}$ were quenched, one from $1,390^{\circ} \mathrm{C}$ and the other from $1,545^{\circ} \mathrm{C}$. On the corresponding X-ray patterns fairly strong lines were found at a position corresponding to an interplanar spacing of $2.12 \mathrm{~A}$ and weak lines were found at $0.942 \mathrm{~A}$. In the patterns of other similar mixtures quenched from similar temperatures, no such lines were observed and, in every pattern obtained, all or all but the weakest lines of the ordinary form of anhydrite were found.

\section{SUMMARY}

The transition of beta calcium sulfate to alpha calcium sulfate occurs at approximately $1,214^{\circ} \mathrm{C}$, but the high-temperature form is unstable and cannot be studied at room temperature. A eutectic mixture appears to be formed by $\mathrm{CaO}$ and alpha $\mathrm{CaSO}_{4}$ which melts at approximately $1,365^{\circ} \mathrm{C}$. The existence of basic sulfates of calcium was not confirmed.

The author acknowledges his indebtedness to Lansing S. Wells for his suggestions and guidance and to Herbert Insley and Howard F. McMurdie, who prepared the photomicrographs and the X-ray patterns. 


\section{REFERENCES}

[1] Kalousek, Jumper, and Tregoning, Rock Products 44, 52 (1941).

[2] Grahmann, Z. anorg. Chem. 81, 257 (1913).

[3] Marchal, J. chim. phys. 23, 38 (1926).

[4] Zawadski, Kowalczewski, and Zeromski, Roczniki Chem. 8, 358 (1928).

[5] Masuda, Proc. Imp. Acad. (Tokyo) 8, 436 (1932).

[6] Carlson, BS J. Research 9, 825 (1932) RP510.

[7] Rankin and Wright, Am. J. Sci. [4] 39, 1 (1915).

[8] Curti, Gazz. chim. ital. 68, 699 (1938).

Washington, June 24, 1941. 